\title{
The Determinants of Information Asymmetry between Managers and Investors: A Study on Panel Data
}

\author{
Younes Boujelbene ${ }^{1}$ and Lobna Besbes ${ }^{2}$ \\ ${ }^{1}$ Economics, Unit of Research URDEE, FSEG, University of Sfax, TUNISIA \\ ${ }^{2}$ Economics, Unit of Research UREA, FSEG, University of Sfax, TUNISIA
}

\begin{abstract}
Thanks to the study of 124 firms listed on the SBF 250 index, the researchers were able to identify the determinants of information asymmetry between firms' managers and investors, using panel data over the period ranging from 1999 to 2008. The results of the random effects model show that most variables are not significant. There is a problem of heteroscedasticity and a problem of autocorrelation. In this regard, the researchers have used the method of generalized least squares to overcome these problems. The results obtained, by using this method, show that the trading volume, as well as the volatility of stock returns, has a positive and significant effect on information asymmetry. The coefficient of the insiders' trading variable is high what shows the relevance of this variable in the explanation of the information asymmetry problem. However, the stock price variable has a negative effect. These results are conclusive to corroborate the thesis of variables relevance resulting from the theory of markets microstructure.
\end{abstract}

Keywords: Information asymmetry, market microstructure theory, volatility of stock returns, insiders' trading.

\section{Introduction}

Recently, the financial markets have witnessed a rapid evolution both institutionally as well as in terms of their activities. Indeed, several reforms have been introduced to meet the new requirements of a rapidly-changing modern world tending to be more sophisticated due to technological progress. In fact, globalization has made the world markets accessible to all investors, worldwide. This has generated a greater financial activity and a more large trading volume.

In fact, the literature pertaining to market microstructure provides a good explanation of this notion of information asymmetry. It takes into account financial market frictions like taxes, transaction costs and fees in order to analyze the relationship between the exchange mechanisms and the price, setting process. These frictions have led to a bid-ask spread that has become the central theme of the microstructure theory. Moreover, microstructure evokes a deep study of the process through which the investors' latent demands are translated in terms of price and volumes (Madhavan, 2000).

Several authors have emphasized the fact that asymmetric information is affected by several factors: the trading volume (Bharath et al., 2009), the volatility of stock returns (Krishnawami and Subrahmanian, 1999) and the insiders' trading (Comerton-

Copyright (C) 2012 Younes Boujelbene and Lobna Besbes. This is an open access article distributed under the Creative Commons Attribution License unported 3.0, which permits unrestricted use, distribution, and reproduction in any medium, provided that original work is properly cited. Contact author: Younes Boujelbene E-mail: younes.boujelbene@fsegs.rnu.tn 
Forde and Rydges, 2006). Along with these factors, the asymmetric information seems to be affected by the transactions probability of the informed as advanced by Easley et al., (1996), the analysts' forecasts (Krishnawami and subrahmanian, 1999) and the firm size (Chae, 2005). In addition, this information asymmetry seems to stem from risky securities. It can be reduced by means of a hierarchical financing established by Myers (1984).

The purpose of this article is to identify the determinants of information asymmetry. In this sense, we will first discuss the financial market microstructure theory. Next, to study the principal cause of the information asymmetry problem and the adopted solution. Then, we will determine the information asymmetry factors. Finally, to treat all aspects of our econometric model: estimation, results and interpretations.

\section{The Theory of Market Microstructure}

It is worth noting that on the academic level, the development of technology and communication media has brought an even greater emphasis on the development of a research field of economics that is largely untapped, namely, the microstructure theory of the financial markets. As a matter of fact, this theory highlights the impact of market frictions on price formation (Madhavan, 2000). The literature of the market microstructure provides an alternative to the Walrasian models pertaining to the transactions' behavior. The assumed perfect competition as well as free trade. These models aim at all the aspects of the securities' transaction process. The earlier literature has focused on the operations carried out by agents known as market makers ${ }^{1}$ who are professional agents buying and selling securities upon request. Microstructure

\footnotetext{
1 Market makers and financial intermediaries are distinct. Financial intermediaries such as banks transform and repackage their assets by buying and selling their liabilities differently from the market maker who buys and sells the same stock. The financial intermediary generally has short or long positions on various stocks.
}

involves the integration of information that depends primarily on the size of declared prices which includes transaction costs, orders and volumes, as well as on the market structure, that is to say its liquidity and its exchange mechanisms and finally on the agents' intervention strategies. Hence, the efficiency seems to be closely associated to the market nature along with the competition of the intervening parties.

Following the literature on microstructure, Bharath et al., (2009) have emphasized the fact that transaction activities could often be measured by the daily volume of exchange. Yet, the latter's application might conceal some essential aspects as it does not provide exact information about the exchange type (i.e. whether it is a purchase or sale) seeing that each of these cases has its specific implications on prices and liquidity. Actually, the distinction between those transactions initiated as purchases and those initiated as sales can possibly be implemented thanks to the recent development of automated quotation systems which allow the delivery of timestamped databases. As a matter of fact, market microstructure literature has been centred around the study of the bid-ask spread as depicted by the relevant two well-known types of theories, namely, the inventory theories as well as the asymmetry ones.

Research on financial market microstructure has largely contributed to the increase of its effectiveness by trying to explain the links that might exist between these market organizational systems, the investors' characteristics and their orderplacing strategies (Sanvi and Caroline, 2008). In addition, it allows the study of an adverse selection between firms' managers and the investors. In fact, the information asymmetry prevails in the case where a certain group holds information and they do not transmit it to another group. The presence of investors holding private information (insiders) engenders an adverse selection problem to the market marker since it changes his behavior and affects the setting up of the bid-ask spread. 
The Information Asymmetry between Managers and Investors: Cause and Solution

Myers (1984) argues that when managers are better informed about investment opportunities than the investors, the market is likely to penalize the issuance of such securities as equities, whose assessment is crucially related to the assessment of such opportunities. Therefore, companies should resort to issuing stocks only as an ultimate step to be taken, after having undergone or implemented some cheaper alternatives (internal cash, bank debt etc.). In other words, the information pertaining to the firm management and concerning the firm's prospects as well as the value of its risky securities vis-a-vis the market, should lead to a financing hierarchy favouring and giving more priority to internal financing rather than to external funding, along with a preference for debts to equities (or proper capitals).

In this respect, information asymmetry can be reduced by means of Myers's (1984) hierarchical funding i.e. cash flow, debt and stock issuance. Cash flow operations allow the strengthening of the financial structure to support a business development. It may also resort to some specialized cashproviding agencies such as banks, and thus getting indebted to them. Actually, cash flow refers to the company's financial state be it stable or fragile. Bernanke and Gertler (1990) show that a fragile situation encourages the company to invest in risky projects and increases the debt-related agency costs (the asset substitution problem). However, Charreaux (1985) highlights the fact that applying selffinancing helps avoid agency costs.

The debt comes in a second place; it plays an important role in reducing the information asymmetry between the managers and the investors. Likewise, it can increase the equity returns of French companies thanks to the leverage effect phenomenon. Besides, it becomes a means of supervising the manager's investment policy through the regular payment of interest and the repayment it implies.
Lastly comes the share issuance. The company makes use of equity financing by means of share issuing driven by its motivation to reinvest the profit earnings. Thus, the hierarchy developed by Myers (1984) looks as follows: internal funds, debt and equity issues. This hierarchy plays an important role in reducing the risk of being caught in situations of underinvestment and share issuance at much reduced prices. Similarly, it may limit the distribution of dividends and reduce capital costs by limiting the recourse to borrowing.

\section{The Determinants of Asymmetric Information}

\section{The Main Determinants of Asymmetric Information}

In this part, we focus on studying the factors affecting the asymmetry of information between the managers and the investors resulting from risky securities, namely: the trading volume, the volatility of stock returns, the insiders' trading and the stock price.

\section{- Trading Volume}

The interplay of supply and demand allows to determine the transaction price of each stock security. In fact, securities are traded for cash, as buyers must have available money and sellers must have stocks. Indeed, the outcome, i. e the payment and delivery of securities, takes place immediately after negotiation. Chae (2005) points out that the trading volume is closely linked with various measures of asymmetric information, and this volume decreases when the earnings are announced. Additionally, Bharath et al., (2009) show that the inverse of the average daily trading volume $\left(T_{i t}^{-1}\right)$ positively influences the asymmetry of information.

H1: There Is a Positive Relationship between the Inverse of the Average Daily Trading Volume and the Information Asymmetry. 


\section{- Stock Return Measures}

Blackwell et al., (1990) use residual volatility in daily stock returns as another proxy for information asymmetry. As for the models of Kyle (1985), pertaining the transactions of the informed and the insiders' expected trading benefits, they are positively related to non-specific assessments of the company's value. Insofar as the residual volatility of stock returns reflects some uncertainty about the company's value, the problem of information asymmetry increases. Fee and Thomas (1999) have mentioned some uncertainty factors for companies such as the rates fixed by the Federal Reserve that are simultaneously relative to both insiders and outsiders.

If the insiders' transactions exceed the abnormal outputs, the superfluous information disclosure entirely does not remove the informational advantage of the leaders (Huddart and $\mathrm{Ke}, 2004)$.There is thus a close connection between stock return and information asymmetry.

\section{H2: There Is a Positive Relationship between the Volatility of Stock Returns and the Information Asymmetry.}

\section{- Insiders' Trading2}

Managers have priority access to private information, related to the liquidation value of an ex-post as risky. They have inside information that could be exploited in their favour. They are potentially able to predict income securities. The insider makes positive profits by exploiting its monopoly power optimally in a dynamic environment where the buzzer provides camouflage that conceals sits activities to

\footnotetext{
2 They are defined as investors who form fully rational expectations about income securities. They check whether the stock has a perfect substitute (that is to say a portfolio of other securities that bring the same income) and whether the stock price equals the price of substitute portfolio. If the stock price falls below the substitute portfolio the arbitrageurs sell-off the portfolio and buy the stock until prices are equalized and vice versa.
}

the market makers. Some authors use the insiders' trading probability as a predictor of information asymmetry between managers and investors (Huddart and Ke, 2004).

Kyle (1985) uses the insiders' trading probability in so much a proxy of information asymmetry. The author argues that when managers are aware of their transactions on the courses, they tend to adopt a strategy of exchange that allows them to conceal information to investors. The informational efficiency is reduced. Several factors limit the disclosure of information so once quoted prices reflect a share of private information including the noise resulting from shocks to liquidity and the strategic behavior of managers (Bias, 1993). If managers take into account their impact on prices, equilibrium prices are not fully revealing (Caballé and Krishnan, 1994). Similarly, Huddart and Ke (2004) note the presence of a close relationship between insiders' transactions and information asymmetry.

\section{H3: There is a Positive Relationship between the Insiders' Trading and the Information Asymmetry.}

\section{- Share Price}

Several studies have shown that the share price explains a significant part of the information asymmetry. Comerton-Forde and Rydge (2006) show that the share price is positively associated with this information asymmetry. Attig et al., (2006) note that the share price is a vector of information, so it negatively affects the information asymmetry. Stoll (1978) shows that the trading volume and the incurred risk affect the cost of detention of market makers. He also notes that the stock price is a proxy for the unobservable minimum cost. In an empirical test, the author finds that the bid-ask spread negatively affects the trading volume while the stock price positively influences the variability of returns. 


\section{H4: There Is a Negative Relationship between the Share Price and the Asymmetric Information.}

\section{Other Determinants of the Asymmetric Information}

In this part, the objective is to analyze the effects of the trading probability of the informed, the analysts' forecasts, the return autocorrelation and the firm size on the information asymmetry existing between the managers and the investors.

\section{- The Trading Probability of the Informed}

Informed traders exchange stocks on the basis of their private signal by seizing more aggressive orders to take advantage of the non-integration of information in prices. The informed agents purchase as soon as the stock is undervalued and sell when it is overvalued. Caballé and Krishman (1994) have indicated that informed investors adopt strategic ways of behavior in order to avoid the disclosure of their private information. At a first stage, they seek to avoid being spotted by the stock exchange operation committee. The informed investors tend to decrease the size of the last concluded orders and spread out their interventions over time. The strategic behavior of those informed shows that the information content depends on their degree of aggressiveness.

The trading probability of the informed $\left(\mathrm{PIN}_{\mathrm{it}}\right)$ has been used by Easley and al. (1996) as an important factor of information asymmetry for those interested in the adverse selection model. Bharath et al., (2009) observe that the greater the trading probability of the informed agents is, the higher the intensity of the information asymmetry on business activity is. This proxy not only shows the perceived advantage of information on financial markets held by the companies' insiders, but also depicts the adverse selection costs, which in turn, affect the costs of emitting information-sensitive values.

\section{- Analysts' Forecast Measures}

Several studies have used derivatives of the analysts' forecasts on earnings per share as proxies for the information asymmetry. Krishnaswami and Subramaniam (1998) use the accuracy of the analysts' forecast pertaining to earnings per share along with the dispersion of the analysts' forecast as proxies for the information asymmetry. The correlation of these measures is based on the results of Blackwell and Dubins (1962) who show that it is essential to distinguish between the amount of known information and the high amount of unknown information. Additional research accomplished by Elton, Gruber and Gultevin (1984) highlight that around 84\% of the forecast error is attributed to the incorrect assessments of enterprises' specific characteristics rather than to economic factors.

Krishnaswami and Subramaniam (1998) have used, as an essential factor of the information asymmetry, the errors of analysts' forecasts to examine the change in the information environment before and after the achievement of an unexpected advantage. They find the firms which get unexpected benefits tend to have high levels of asymmetric information and that the latter decreases significantly following the completion of this advantage.

Since the forecast error can prove to be costly for firm managers (legal sanctions and penalties by the market), they are likely to seek some ways and means to reduce it (Cormier and Magnan 1997). These authors have found that when a significant deviation between the forecasts and the achievements appears, leaders tend to manage their earnings in a subsequent way to the filing. Hence, these authors have tested this hypothesis on a sample comprising 120 Canadian firms listed in the stock market between 1985 and 1992. The Canadian case seems to be interesting because firm managers are able to issue forecasts in prospectuses. 
Businesses willing to make projected profits are faced with two constraints. On the one hand, auditors must express their opinion on the validity of the managers' selected assumptions before the publication of such information. On the other hand, in case of significant error, companies are required to justify and account for the discrepancies in the financial statements.

\section{- Return Autocorrelation}

Clarke and Shastri (2001) identify the interaction between the trading volume and the stock returns by means of $\hat{C}_{2 \mathrm{it}}$, used as a robust proxy for information asymmetry. More specifically, and in consistence with Liorente et al., (2002), this coefficient needs to be positive and significant for the stocks around which speculation is important. It shows the importance of speculation while protecting the stock returns. The empirical work carried by Bharath et al., (2009), concerning some U.S. equities over the period 1973-2002, have come to the conclusion that the autocorrelation of returns positively influences the asymmetric information between the managers and the investors. This coefficient is calculated as follows:

$R_{i t}(k+1)=C_{0 i t}+C_{1 i t} r_{i t}(k)+C_{2 i t} V_{i t}(k) r_{i t}(k)+\eta_{i t}(k)$

With $V_{i t}(k)$ : Log of trading volume of the day $\mathrm{k}$ for the year $\mathrm{t}$;

$r_{i t}(k)$ : Stock returns of the day $\mathrm{k}$ for the year t;

$\eta_{i t}(k)$ : Residual error term, with $\mathrm{i}=1 \ldots \mathrm{T}, \mathrm{t}$ $=1 \ldots \mathrm{T}$ and $\mathrm{k}=1 \ldots \mathrm{T}$.

\section{- Firm Size}

Asymmetric information can also be measured by the firm size. Indeed, Chae (2005) found that small firms have higher information asymmetry than large firms. Demsetz (1986) notes that small firms have high amounts of internal information and wide bid-ask spreads due to the low number of insiders. Some researchers measure the firm size by the logarithm of the market capitalization of the firm, calculated at the end of each trading day and reduced to an average (Randi, 2004; Comerton-Forde and Rudge, 2006). Others measure the firm size by the logarithm of the market capitalization at the end of December each year (Chae, 2005; Lafond et al., 2007).

\section{Selected Sample, Variables Measurement, Model Presentation, Results and Interpretations}

\section{Selected Sample, Variables Measurement and Model Presentation}

Our empirical study covers a sample consisting of 124 French firms listed on the SBF 250 index over the period ranging from 1999 to 2008. We have obtained the data from the data base "Datastream" and financial reports, seen in the sites "Euronext". The data have allowed us to properly calculate and specify our model's variables so as to explain the asymmetry of information lying between managers and investors.

Our model is written, for each stock $\mathrm{i}(\mathrm{i}=1$ ........ T), as follows:

$A S Y_{i t}=\alpha_{i t}+\beta_{1 i t} T_{i t}^{-1}+\beta_{2 i t} V R+\beta_{3 i t} I T_{i t}+\beta_{4 i t} P R I C E_{i t}+\varepsilon_{i t}$

With $A S Y_{i t}$ : The information asymmetry is measured by Roll (1984)'s effective bid-ask spread $^{3}$, which is calculated on daily basis then brought back on average during the yeart :

$R S_{i t}=$

$\left.\operatorname{mo}\left\{20 \alpha_{i t} \sqrt{-\operatorname{cov}\left(\xi_{i t}(k), r_{i t}(k-1)\right)}-20 \emptyset 1-I_{i t}\right) \sqrt{\operatorname{cov}\left(\xi_{i t}(k), r_{i t}(k-1)\right)}\right]$

Where $\operatorname{cov}\left(\mathrm{r}_{\mathrm{it}}(\mathrm{k}), \mathrm{r}_{\mathrm{it}}(\mathrm{k}-1)\right)$ is the covariance of daily stock returns' during the year $\mathrm{t}$; $\mathrm{I}_{\mathrm{it}}=1$ if $\left[\operatorname{cov}\left(\mathrm{r}_{\mathrm{it}}(\mathrm{k}), \mathrm{r}_{\mathrm{it}}(\mathrm{k}-1)\right)\right]<0$ and $\mathrm{I}_{\mathrm{it}}=0$ otherwise.

$T_{i t}^{-1}$ : The inverse of daily trading volume, calculated on average during the year $t$;

3 The information asymmetry is measured by Roll (1984)'s model $\left(\mathrm{RS}_{\mathrm{it}}\right)$ for any stock i over day $\mathrm{k}$ in year 
$V R_{i t}$ : The standard deviation of the daily stock returns, calculated on average during year t;

$I T_{i t}$ : The ratio of the sum of purchases and sales of insiders ${ }^{4}$ and the trading volume, calculated on average during the year $t$;

PRICE $E_{i t}$ Logarithm of the average daily closing share price during year $t$;

$\varepsilon_{i t}$ : Error corresponding to the equation, with $\mathrm{i}=1 \ldots \mathrm{T}$ and $\mathrm{t}=1 \ldots \mathrm{T}$;

$\beta_{1 i t}, \beta_{2 i t}, \beta_{3 i t}, \beta_{4 i t}$ : Weight of each exogenous variable on the endogenous variable ASY;

$\alpha_{i t}$ : The model constant.

\section{Results and Interpretations}

Before testing the significance of the variables, we reckon it necessary to apply the Hausman test to estimate the correlation between individual effects and explanatory variables. This specification test follows Chi-square law with K-1 degree of freedom and helps determine whether to use a fixed effect model or a random effect one. From the Hausman test, we may sort out two hypotheses: If this test probability proves to be greater than $5 \%$, it is then not significant and leads to favour that model retaining specific random effect in which case the GLS is to be adopted. Otherwise, we opt to use the fixed effect model which makes the object of our study.

- Results of Random Effects Model Estimates and Their Interpretations

${ }^{4}$ CEOs, Directors 
Table 1: Results of the Random Effect Model

\begin{tabular}{|l|c|c|c|c|c|c|c|}
\hline ASY & Coef & Mean & Std Err & $\mathbf{t}$ & Prob & [ 95\% Conf & Interval ] \\
\hline T-1 & .3874526 & 1.8844357 & .9326684 & 0.41 & 0.622 & -1.396542 & 2.185642 \\
\hline VR & .0218595 & .3942273 & .1936582 & 0.64 & 0.544 & -.0324108 & .0621439 \\
\hline IT & .6474525 & .163492 & .076203 & 8.92 & 0.000 & .5049589 & .7899461 \\
\hline PRICE & - & .3118293 & .2006241 & -0.31 & 0.704 & -.4032114 & .3074521 \\
& .0596854 & & & & & & \\
\hline Cons & .0635455 & .0781474 & .0425636 & 2.07 & 0.000 & .0132556 & .1236596 \\
\hline
\end{tabular}

While referring to the estimation results, the information asymmetry increases the trading volume. The inverse of the trading volume, the volatility of stock returns and the stock price are not significant. From this result, the hypothesis $H 1, H 2$ and $H 4$ could not be assessed. The variable insiders' trading presents a positive and significant sign of $1 \%$ for the random effects model. The results found related to this variable support the conclusions of Kini and Mian (1995) which show that information asymmetry is positively related to the insiders' trading. These results are consistent with those of Bharath et al., (2009) show that, using a database merged CRSP-COMPUSTAT of the American stocks for the period 1973-2002, the insiders' transactions is a significant explanatory variable of information asymmetry. The increase in purchases and sales of insiders encourage them not to disclose the information required for transactions resulting in the increase in information asymmetry.

\section{- Problems of Heteroscedasticity and Autocorrelation}

Once the model has been estimated, a problem of heteroscedasticity arises because the variance of model residuals is not constant. This variance does not bias the coefficients estimated by OLS though it shows the inefficiency of the model coefficients. Since the standard deviations obtained are over-estimated or underestimated, we can use a table to compare the value obtained with the critical values of the statistics concerned.

To detect heteroscedasticity, we can use the test of Breusch-Pagen and the test of White. Both tests refer to the Fisher test. They can check if the squared residuals can be explained by model variables. The adoption of this hypothesis shows the presence of heteroscedasticity. The null hypothesis assumes that all the coefficients of the regression of squared residuals are zero, which implies homoscedasticity. The alternative hypothesis assumes that there is heteroscedasticity.

The test of inter-individual heteroscedasticity is designed to test the specific hypothesis of inter-individual homoskedasticity. The Software STATA uses a modified Wald test, a(n) F test in particular. Under the null hypothesis, the test contemplates that the error variance is the same for all individuals and the statistic follows a $\chi 2$ law with an $\mathrm{N}$ freedom degree. When the value obtained is lower than the critical value, we can not reject the null hypothesis: the error variance is similar for all individuals. In our case, we can detect the presence of heteroscedasticity problems using the test of Breusch-Pagen. 
Table 2: Heteroscedasticity Test

\begin{tabular}{|l|c|c|c|c|c|c|}
\hline ASY & Coef & Std Err & t & Prob & [ 95\% Conf & Interval ] \\
\hline T-1 & .0398752 & .0010342 & 372.73 & 0.000 & .4015633 & .4052336 \\
\hline VR & .0142263 & .0000142 & 741.12 & 0.000 & .0135608 & .013852 \\
\hline IT & .4018992 & .0009825 & 387.55 & 0.000 & .3915822 & .3959066 \\
\hline PRICE & -.0692541 & .0002135 & -327.64 & 0.000 & -.0725631 & -.0626547 \\
\hline Cons & .1620553 & .0003125 & 521.23 & 0.000 & .1701124 & .1712236 \\
\hline \multicolumn{7}{|c|}{$F(4,1235)=71847.14 ;$ Prob > F = 0.0000 } \\
\hline
\end{tabular}

It is also essential to show the presence of a problem of autocorrelation through the calculated F statistic.

Table 3: Autocorrelation Test

\begin{tabular}{|l|c|c|c|c|c|c|}
\hline $\mathbf{u}$ & Coef & Std Err & t & Prob & [95\% Conf & Interval ] \\
\hline L1 & -1.000215 & .3542585 & -2.42 & 0.010 & -1.739856 & -.2438256 \\
\hline L2 & 2.00954 & .1658223 & 11.94 & 0.000 & 1.69859 & 2.345299 \\
\hline L3 & .598113 & .0872653 & 6.77 & 0.000 & .41175 & .7698521 \\
\hline L4 & .0339856 & .3525891 & 0.08 & 0.914 & -.6850141 & .7662065 \\
\hline Cons & .039627 & .0077255 & 5.04 & 0.000 & .0221475 & .0598873 \\
\hline \multicolumn{7}{|c|}{ Prob > F = 0.0000 } \\
\hline
\end{tabular}

To correct these two problems, we have opted for the Generalized Least square technique to overcome the existence of heteroscedasticity problem as well as the problem of inter-individual autocorrelation of a first order autoregression type.

- Results of Estimates by the Method of Least Squares Generalized and Their Interpretations

Table 4: Regression Results via GLS

\begin{tabular}{|l|c|c|c|c|c|c|}
\hline ASY & Coef & Std Err & t & Prob & [ 95\% Conf & Interval ] \\
\hline T-1 & .602057 & .0862541 & 6.62 & 0.000 & .4553681 & .7814265 \\
\hline VR & .16011 & .074852 & 1.87 & 0.052 & -.0029854 & .3320482 \\
\hline IT & .9542336 & .2745513 & 3.22 & 0.005 & .3125633 & 1.596603 \\
\hline PRICE & -.4542522 & .0058236 & -2.08 & 0.029 & -.4830815 & -.4536251 \\
\hline Cons & .0158256 & .011325 & 1.39 & 0.162 & -.0062775 & .0388524 \\
\hline \multicolumn{7}{|c|}{ Wald chi2(4) $6.88 ;$ Prob > chi2 $=0.0643$} \\
\hline
\end{tabular}

The results obtained using the GLS show changes in the degree of significance of variables except that of the insiders' trading of which remains significant at a $1 \%$ level. The performed regression shows that the variable coefficient $\left(T_{i t}^{-1}\right)$ is positive, though significant. This result differs from the conclusions reached by Chae (2005) which demonstrate a negative and significant coefficient at a 5\% level. But, it is consistent with our hypothesis $H 3$ which states that the inverse of the average daily trading volume positively affects the 
information asymmetry between managers and investors.

The stock returns volatility variable shows a positive and significant sign of $10 \%$ for GLS. The stock returns volatility is frequently used by the investors like a measuring instrument of the selection adverse problem. The principal reason of the realization of positive returns is the insiders' privileged access to information. That enables them to know the moment when the shares are undervalued. The obtained results pertaining to this variable consolidate the conclusions reached by Van et al., (2001) as opposed to those of Chung and $\mathrm{Li}$ (2003).

Through the use of Generalized Least Square technique, the insiders' trading variable remains significant. Its very high coefficient indicates the importance of this variable in the explanation of the information asymmetry. This result is consistent with that of Jabbour et al., (2000) who find that the insiders' trading, on the Canadian market, increase the information asymmetry.

The stock price has a negative effect on the information asymmetry. This confirms the hypothesis $\mathrm{H} 4$ which supposes the presence of a negative relationship between the share price and the information asymmetry. The found result confirms the one found by Comerton-Forde and Rydge (2006) but it contradicts the result found by Attig et al., (2006).The high coefficient of the stock price shows the major role of this variable in the explanation of the information asymmetry.

\section{Conclusion}

Our study examines the determinants of information asymmetry between managers and investors which are trading volume, stock returns volatility, insiders' trading and stock price. The results, following the estimation of our basic model, show that the increased trading volume leads to an increase in information asymmetry. The stock returns volatility is a relevant factor in the explanation of the adverse selection problem. The coefficient of the insiders' trading variable is high what shows the importance of this variable in the explanation of the information asymmetry problem in relation to other variables. The stock price is an indicator of information which shows the inverse relationship between this variable and adverse selection problem.

\section{References}

Attig, N., Fong, W.- M., Gadhoum, Y. \& Lang, L. H. P. (2006). "Effects of Large Shareholding on Information Asymmetry and Stock Liquidity," Journal of Banking and Finance, 30, 2875-2892.

Bernanke, B. \& Gertler, M. (1990). "Financial Fragility and Economic Performance," The Quarterly Journal of Economics, MIT Press, 105, 87-114.

Bharath, S. T., Pasquariello, P. \& Wu, G. (2009). "Does Asymmetric Information Drive Capital Structure Decisions?," Review of Financial Studies, 22, 3211-3243.

Blackwell, D. \& Dubins, L. (1962). "Merging of Opinions with Increasing Information," Annals of Mathematical Statistics, 33, 882886.

Blackwell, D. W., Marr, M. W. \& Spivey, M. (1990). "Shelf Registration and the Reduced due Diligence Argument: Implications of Underwriter Certification and the Implicit Insurance Hypotheses," Journal of Financial and Quantitative Analysis, 25, 245-259.

Caballé, J. \& Krishnan, M. (1994). "Imperfect Competition in a Multi-Security Market with Risk Neutrality," Econometrica, 62, 695-705.

Chae, J. (2005). "Trading Volume, Information Asymmetry, and Timing Information," The Journal of Finance, 61, 413-442.

Clarke, J. \& Shastri, K. (2001). "On information Asymmetry Metrics," Working Paper, Katz Graduate School of Business, University of Pittsburgh. 
Comerton-Forde, C. \& Rydge, J. (2006). "Director Holding, Sharehoder Concentration and Illiquidity," Working Paper, University of Sydney NSW 2006.

Cushing, D. \& Madhavan, A. (2000). "Stock Returns and Trading at the Close," Journal of Financial Markets, Elsevier, 3, 45-67.

Demsetz, H. (1968). "Corporate Control, Insider Trading and Rates of Return," American Economic Review, 3-16.

Easley, D., Kiefer, N. M., O’Hara, M. \& Paperman, J. B. (1996). "Liquidity, Information, and Infrequently Traded Stocks," Journal of Financial Economics, 19, 69-90.

Freese, J., Li, J.- C. A. \& Wade, L. D. (2003). "The Potential Relevances of Biology to Social Inquiry," Annual Review of Sociology, 29, 233-56.

Hausman, J. A. (1978). "Specification Tests in Econometrics," Econometria, 46, 12511271.

Krishnaswami, S. \& Subramaniam, V. (1999). "Information Asymmetry, Valuation, and the Corporate Spin-Off Decision," Journal of Financial Economics, 53, 73-112.

Kyle, A. S. (1985). "Continuous Auctions and Insider Trading," Econometrica, 6, 1315-1335.

LaFond, R., Lang, M. \& Skaife, H. (2007). "Earnings Smoothing, Governance and Liquidity: International Evidence," Working paper, University of North Carolina.

Liorente, G., Michaely, R., Saar, G. \& Wang, J. (2002). "Dynamic Volume-Return Relation of Individual Stocks," Review of Financial Studies, 15, 1005-1047.

Magnan, M. \& Cormier, D. (1997). 'The Impact of Forward-Looking Financial Data in IPOs on the Quality of Financial Reporting,' The Journal of Financial Analysis, Spring, 6-17.
Myers, S. C. (1984). "The Capital Structure Puzzle," Journal of Finance, 39, 575-592.

Næs, R. (2004). "Ownership Structure and Stock Market Liquidity," Norges Bank, Publications, Working paper, May, 2008.

Roll, R. (1984). “A Simple Implicit Measure of the Effective Bid-Ask Spread in an Efficient Market," Journal of Finance, 39, 1127-1139.

Stoll, H. R. (1978). "The Pricing of Security Dealer Services: An Empirical Study of NASDAQ Stocks," The Journal of Finance, 1153-1173.

Thomas, S. \& Fee, C. E. (2000). “Corporate Diversification, Asymmetric Information, and Firm Value: Evidence from Stock Market Trading Characteristics," Working Paper. Michigan State University.

Van Ness, B. F., Van Ness, R. A. \& Warr, R. S. (2001). "How Well do Adverse Selection Components Measure Adverse Selection," Journal of Finance, 55(6), 2565-2598. 